\title{
Smart Spectrophotometric Method Development for Simultaneous Estimation of Antidiabetic Drugs in Formulations
}

\author{
Mahesh Attimarad ${ }^{1, *}$, Katharigatta Narayanaswamy Venugopala ${ }^{1,2}$, Sheeba Shafi, \\ Abdulmalek Ahmed Balgoname ${ }^{1}$, Abdulrahman Ibrahim Altaysan ${ }^{1}$ \\ ${ }^{1}$ Department of Pharmaceutical Sciences, College of Clinical Pharmacy, King Faisal University, Al-Hofuf, Al-Ahsa, SAUDI ARABIA. \\ 2Department of Biotechnology and Food Science, Faculty of Applied Sciences, Durban University of Technology, \\ Durban, SOUTH AFRICA. \\ ${ }^{3}$ Department of Nursing, College of Applied Medical Sciences, King Faisal University, AI Ahsa, SAUDI ARABIA.
}

\begin{abstract}
Background: An anti-diabetic formulation consisting of vildagliptin and remogliflozin was prescribed for better glycemic control. In the present study a simple, rapid derivative spectrophotometric methods were evolved to analyze these two analytes from the formulations. Methods: Two processed UV spectrophotometric methods were established by measuring the peak amplitude at zero-crossing of second derivative spectra of analytes. The second procedure comprehends the generation of zero - order spectra from the mixture of analyte spectra by division and multiplication by the pure analyte spectra to remove the effect of one of the analytes. Results: Both methods showed linearity concentrations in the range of $2-75 \mu \mathrm{g} / \mathrm{ml}$ for RGF and $2-50 \mu \mathrm{g} / \mathrm{ml}$ for VGT. The low LOD and LOQ found for RGF and VGT by both methods indicated the good sensitivity of the methods. The mean percentage recovery was $98.60 \%$ and $100.78 \%$, for RGF and $98.81 \%$ and $99.15 \%$ for VGT, with low percent relative error. The \% RSD for intra and inter-day precision was less than $\pm 2 \%$. Finally, the planned methods were employed for the assay of the VGT and RGF from the medicine and the outcomes were matched with the reported methods. Conclusion: The assay results of the formulation were in agreement with the concentration of labeled amount and no significant difference was observed in the results when compared to the reported method. Hence, the anticipated procedures could be applied for the routine quality control of formulations consisting of VGT and RGF.
\end{abstract}

Key words: Antidiabetics, Vildagliptin, Remogliflozin, Derivative spectrophotometry, Formulation, Validation.

\section{INTRODUCTION}

The number of patients with diabetes mellitus is increasing rapidly worldwide A recent study by the World Health Organization reported that the occurrence of diabetes mellitus type 2 was more than $30 \%$. Hence, to avoid the diabetic complications monitoring normal blood sugar levels is a key factor in type 2 diabetic patients. In patients with type 2 diabetes, the first line of treatment with metformin did not reduce $\mathrm{HbA1c}$ levels below the targeted level, second pharmacological agents like dipeptidyl peptidiase-4 (DDP-4) inhibitors and sodium glucose cotransporter-2 (SGLT-2) inhibitors are prescribed. ${ }^{1}$ Several DPP4 inhibitors ${ }^{2}$ and SGLT2 inhibitors ${ }^{3}$ that offer strong glycemic control have been prescribed alone or along with other antidiabetic drugs. According to a study by Ahsan $\mathrm{S}^{4}$ vildagliptin in combination with remogliflozin will help to achieve the targeted $\mathrm{HbA}_{1 \mathrm{c}}$ level. Hence, a single tablet consisting of vildagliptin $(50 \mathrm{mg}$ ) and remogliflozin (100 mg) was sanctioned by FDA because of its simpler regime for better glycemic control. Further both
Submission Date: 10-06-2021; Revision Date: 14-09-2021; Accepted Date: 15-12-2021.

DOI: 10.5530/ijper.56.1.26 Correspondence:

Dr. Mahesh Attimarad Associate Professor, Department of Pharmaceutical Sciences, College of Clinical Pharmacy, King Faisal University, Al Ahsa, KSA.

E-mail: mattimarad@kfu. edu.sa

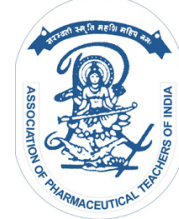

www.ijper.org 


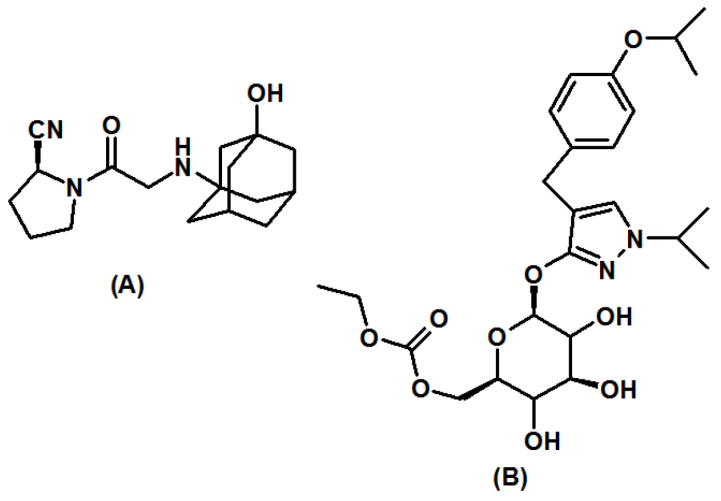

Figure 1: Chemical structure of vildagliptin(A) and remogliflozin etabonate (B).

the analytes act by different mechanism of action and insulin independent. Vildaglitpin (VGT, Figure 1A) a selective, orally active reversible DPP4 inhibitor, acts by inhibiting DPP-4 enzyme responsible for the breakdown of glucagon-like peptide-1 (GLP-1). ${ }^{2,5}$ This enhances the secretion of insulin and reduces the secretion of glucagon resulting in a reduction in blood glucose levels. In addition, VGT is well tolerated, does not have any effect on body weight, has no hypoglycemic effect and can be used in patients with kidney problems.,

Remogliflozin etabonate (RGF, Figure 1B) is the latest SGLT-2 inhibitor, used for the management of type 2 diabetes prescribed alone and with other antidiabetic agents. RGF reduce the blood glucose level by inhibiting the reabsorption of glucose from the renal tubule and independent of effecting the insulin release. In addition, RGF help in declining the body weight and bloodpressure due to increase in the excretion of glucose and water. ${ }^{2,7}$

A number of assay procedures have been described for the assessment of VGT and RGF from different matrix including medicines. VGT has been estimated using UV-Vis spectrophotometry, ${ }^{8-12}$ HPLTC, ${ }^{13}$ HPLC, ${ }^{14,15}$ and LCMS $^{16}$ alone and with other antidiabetic agents. The analysis of RGF by spectrophotometry, ${ }^{17-20}$ HPLC, ${ }^{19-}$ ${ }^{22}$ UPLC, $^{23}$ and $\mathrm{LC}^{-\mathrm{MS}^{24}}$ has been reported in the literature. Nevertheless, no quantitative assay method has been described for the concurrent quantification of VGT and RGF from the formulation. Hence, in the present work, we plan to establish simple, sensitive and robust derivative spectrophotometric methods for the quantification of VGT and RGF from combined medicine and validated according to the $\mathrm{ICH}$ guidelines.

\section{MATERIALS AND METHODS}

Spectrophotometric measurements were performed using double-beam UV-Vis spectrophotometer
(1600, Shimadzu, Japan). The cuvettes used for the measurements were quartz and one $\mathrm{cm}$ in width. The instrument was set for fast scanning with $0.1 \mathrm{~nm}$-slit width. The scanned spectra were processed using UV Probe software (Ver. 2.2). The standard drug and tablets were weighed using a Shimadzu digital weighing scale (Japan). Volumetric flasks used for preparation of standard solutions and sample solutions were calibrated before use.

Standard analytes of vildagliptin and remogliflozin etabonate were purchased from Biokemix India Ltd. (Hyderabad, India). Analytical-grade ethanol used for the preparation of standard solution was purchased from Sigma Aldrich. Pure water used for the dilution of standard and sample solutions was prepared using Milli Q water purifier (Millipore, USA).

\section{Preparation of standard solutions}

Standard solutions of VGT and RGF $1 \mathrm{mg} / \mathrm{ml}$ were prepared using water and ethanol respectively. Further standard solutions were diluted using water to obtain a concentration in the linearity range.

\section{Preparation of sample solution}

The medicine consisting of VGT and RGF was not available in the local market, hence a physical mixture consisting of VGT, RGF and all tablet excipients was prepared by geometrically adding sufficient amount VGT, RGF, sodium carboxy-methylcellulose, microcrystalline cellulose, anhydrous lactose, and magnesium stearate. Powder equal to $5 \mathrm{mg}$ of VGT and $10 \mathrm{mg}$ RGF was placed into a $10 \mathrm{ml}$ graduated flask and extracted with ethanol to get $0.5 \mathrm{mg} / \mathrm{ml}$ of VGT and $1 \mathrm{mg} / \mathrm{ml}$ of RGF respectively.

\section{Procedures}

\section{Second derivative spectrophotometric method (SDS)}

Working standard solutions $(10 \mathrm{ml})$ of VGT $(2,10,20$, $30,40$ and $50 \mu \mathrm{g} / \mathrm{ml})$ and RGF ((5, 15, 30, 45, 60 and $75 \mu \mathrm{g} / \mathrm{ml}$ ) were prepared separately by adding sufficient amounts of VGT and RGF solutions respectively. A sufficient amount of ethanol was also added to each volumetric flask to maintain an equal amount $(250 \mu \mathrm{L})$ of ethanol in each volumetric flask. After that, the absorption spectra were measured for each solution by scanning at a wavelength range of $200-300 \mathrm{~nm}$. Subsequently, the second-order derivative spectra of VGT and RGF were generated from the zero-order spectra using UV-Probe software. The peak amplitudes of the second-order derivative spectra were monitored at $221.3 \mathrm{~nm}$ and $243.4 \mathrm{~nm}$ for VGT and RGF respectively. 
Further, calibration plots were created by plotting the peak amplitudes against analyte concentration and corresponding regression equations were derived.

\section{Constant centered spectrophotometric method (CCS)}

Working standard solutions consisting of $2-50 \mu \mathrm{g} / \mathrm{ml}$ of VGT and $5-75 \mu \mathrm{g} / \mathrm{ml}$ of RGF were organized in $10 \mathrm{ml}$ graduated flasks. After that, the absorption spectra were measured for each solution by scanning at a wavelength range of $200-300 \mathrm{~nm}$. Separately $5 \mu \mathrm{g} / \mathrm{ml}$ of VGT and RGF were prepared and absorption spectra were recorded. The absorption spectra of VGT and RGF were divided by the spectrum of $5 \mu \mathrm{g} / \mathrm{ml}$ of VGT and RGF separately to obtain the ratio spectra of RGF and VGT respectively. The resulting ratio spectra of VGT and RGF were multiplied with $5 \mu \mathrm{g} / \mathrm{ml}$ of RGF and VGT spectra to generate the original spectra of VGT and RGF correspondingly. The absorption was calculated at $208 \mathrm{~nm}$ and $225.8 \mathrm{~nm}$ for VGT and RGF correspondingly. The calibration curves (Figure $2 \mathrm{c}$ and $2 \mathrm{~d}$ ) were generated by plotting the absorption against the analyte concentration and regression equations were computed.

\section{Application to medical dosage forms}

Above prepared formulation, solutions were diluted with water to obtain the concentrations of VGT and RGF in the linear range. The UV absorption spectra were measured by scanning at a wavelengths between 200-300 nm. Subsequently, the spectra were processed into second -order derivative spectra and the peak amplitudes were measured at $243.4 \mathrm{~nm}$ for RGF and $221.3 \mathrm{~nm}$ for VGT. The quantity of analytes was computed using the respective regression equations. Further, for the CCS method, the zero-order spectra of VGT and RGF were generated using the CCS method described above. The peak absorption was determined at $208 \mathrm{~nm}$ and $225.8 \mathrm{~nm}$ for VGT and RGF correspondingly and the amount of analytes was determined from the corresponding regression equations.

\section{RESULTS AND DISCUSSION}

In general, derivative spectrophotometric methods have been applied for the quantification of mixtures of compounds with overlapping spectra. ${ }^{25-30}$ The derivatization technique is a sensitive, rapid and accurate technique for the concurrent determination of multicomponent formulations. Derivatization removes the absorption of one of the components at the zerocrossing point and allows the quantification of another component. ${ }^{25,26}$ In the present work, RGF and VGT showed complete overlap (Figure 2A); hence, they were changed into $2^{\text {nd }}$ derivative spectra using a scaling factor of 100 (Figure 2B). Different wavelengths from $2 \mathrm{~nm}$ to $8 \mathrm{~nm}$ were envisaged as $\Delta \lambda$; however, $4 \mathrm{~nm}$ showed smooth spectra, hence, $4 \mathrm{~nm}$ was selected as $\Delta \lambda$. VGT showed zero crossing points at $208.2 \mathrm{~nm}, 243.4 \mathrm{~nm}$, where RGF had some absorption, however, at the 243.3 $\mathrm{nm}$ selectivity was better hence, $243.3 \mathrm{~nm}$ was selected for further study. RGF showed two zero crossing points at $235.1 \mathrm{~nm}$ and $221.3 \mathrm{~nm}$ where VGT had some absorption. However, at $221.3 \mathrm{~nm}$ the peak amplitude and selectivity were better, hence 221.3 was selected for further study. Standard UV absorption spectra of VGT and RGF were converted in to second derivative spectra (Figure $3 \mathrm{~A}$ and $3 \mathrm{~B}$ ). Farther, the peak amplitude of second derivative spectra of pure and mixture showed same amplitude at $221.3 \mathrm{~nm}$ for VGT (Figure 2B) and at $243.3 \mathrm{~nm}$ for RGF (Figure 2B).

Constant center spectrophotometric method is another simple technique used for simultaneous quantification of analytes present in mixture. In this method, for the quantification of RGF, UV absorption spectra were recorded for the mixture of analytes (VGT+RGF) and divided by the spectrum of one of the analytes $(5 \mu \mathrm{g} / \mathrm{ml}$ UV spectrum of VGT). The obtained ratio
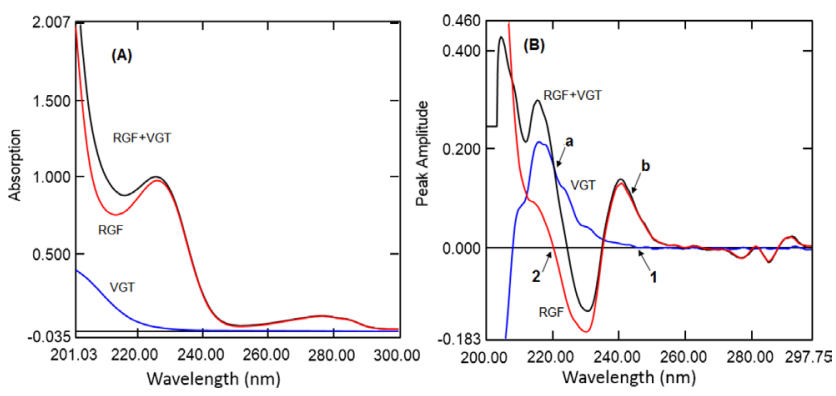

Figure 2: Zero-order spectra of VGT, RGF and mixture (A). Second derivative spectra of VGT, RGF and mixture showing zero crossing points of VGT (1) and RGF (2) along with same absorption for VGT (a) and RGF (b) form pure and mixture spectra.
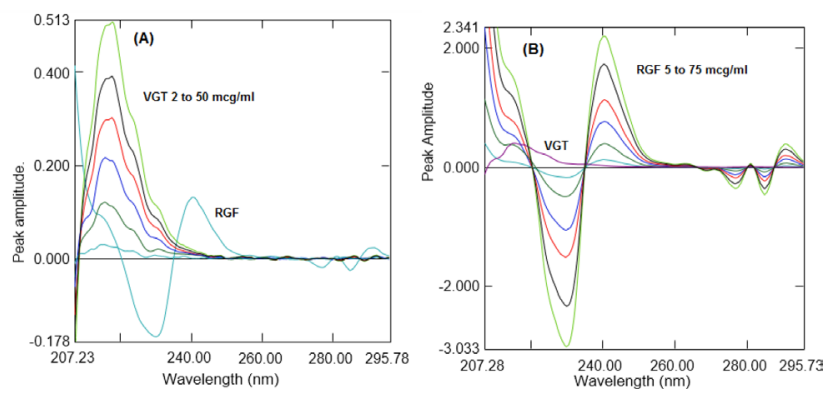

Figure 3: second order derivative spectra of VGT (2 to $50 \mu \mathrm{g} / \mathrm{ml}$ ) (A) and RGF (5 to $75 \mu \mathrm{g} / \mathrm{ml}$ ) Constant center spectrophotometric method. 


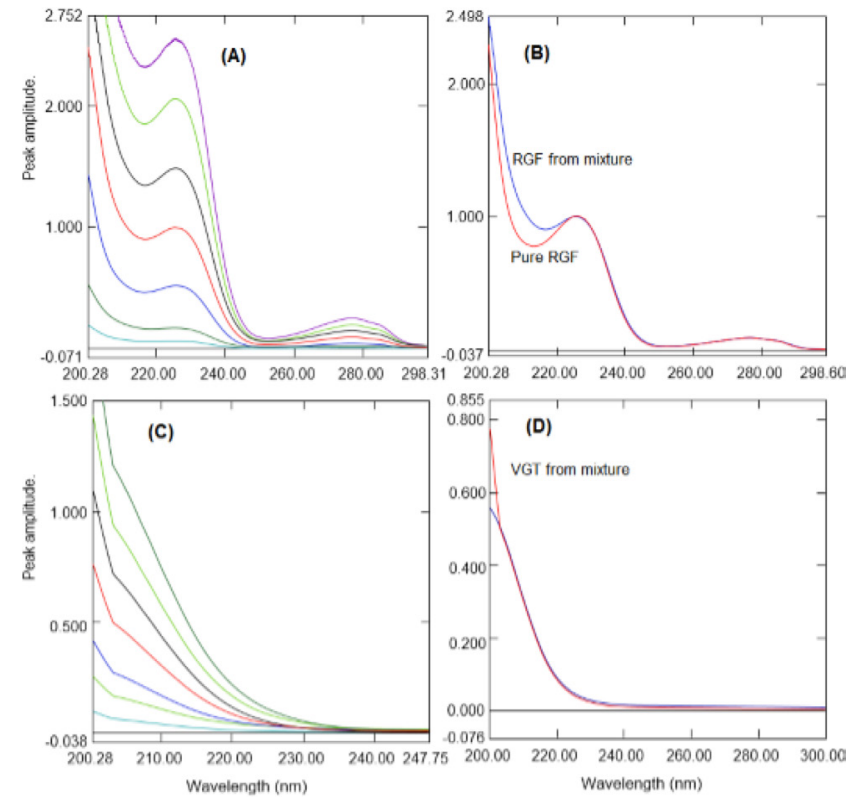

Figure 4: Zero-order spectra of RGF (2 to $75 \mu \mathrm{g} / \mathrm{ml}$ ) developed by dividing the mixture by the spectrum of VGT $(5 \mu \mathrm{g} / \mathrm{ml})$ followed by multiplication with the spectrum of VGT (A). Zero-order spectra of VGT ( 2 to $50 \mu \mathrm{g} / \mathrm{ml}$ ) were developed by dividing the mixture by the spectrum of RGF $(5 \mu \mathrm{g} / \mathrm{ml})$ followed by multiplication with the spectrum of $\operatorname{RGF}(\mathrm{C})$. Zero-order spectra generated from mixture and pure RGF (B) and VGT (D).

spectra illustrate the RGF/VGT+ constant. The zeroorder spectra of RGF (Figure 4A) can be obtained by multiplying the resulting ratio spectra with the same VGT spectra. The calibration plot was generated by measuring the peak amplitude at $225.8 \mathrm{~nm}$ against corresponding concentration of $\operatorname{RGF}(2,5,15,30$, 45, 60 and $75 \mu \mathrm{g} / \mathrm{ml}$ ) and regression equations were computed. The spectrum generated from the mixture and pure analytes showed the same absorption at 225.8 $\mathrm{nm}$ (Figure 4B).

Similarly, VGT zero-order spectra (Figure 4C) were generated by dividing the mixture spectra with the RGF spectrum, followed by multiplication of the ratio spectra with the RGF spectrum $(5 \mu \mathrm{g} / \mathrm{ml}$ UV spectrum of RGF). Calibration plots and regression equations were generated using peak amplitude at $208.0 \mathrm{~nm}$ and corresponding concentrations $(2,5,10,20,30,40$ and $50 \mu \mathrm{g} / \mathrm{ml})$. Further, the zero-order spectra generated from the mixture and pure VGT showed the same absorption at $20.0 \mathrm{~nm}$ (Figure 4D).

\section{Method validation}

Validity of the proposed derivative methods were confirmed by performing linearity, limit of detection, limit of quantification, accuracy, precision and stability studies as per the ICH guidelines.
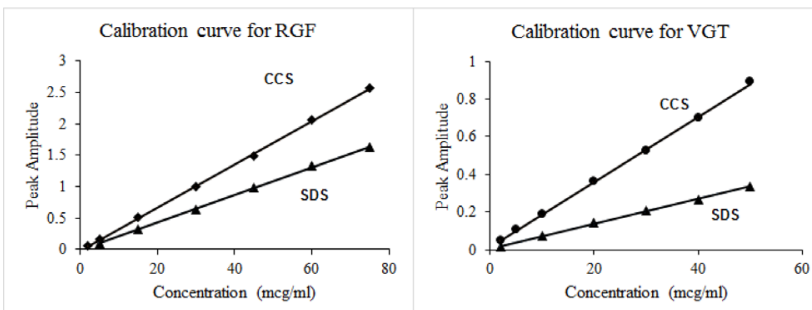

Figure 5: Calibration curve for RGF(A) and VTG(B) by both the second derivative spectroscopic (SDS) and constant-centered spectroscopic (CCS) methods.

\section{Linearity}

The calibration plot provides important information about the linearity of the proposed method. In the present study linearity range was studied in the concentration range of $5-75 \mu \mathrm{g} / \mathrm{ml}$ using the SDS method and $2-75 \mu \mathrm{g} / \mathrm{ml}$ by the CCS method for RGF (Figure $5 \mathrm{~A}$ ). VGT exhibited excellent linearity in the range of 2 to $50 \mu \mathrm{g} / \mathrm{ml}$ by both the methods (Figure 5B). The regression equations and regression coefficients are listed in Table 1.

\section{Limit of detection and quantification limits}

The detection and quantification limits were estimated using the linearity curve parameters. The LOD was calculated as 3.3 times the standard deviation of the intercept to the slope of the curve. The LOQ was 10 times the standard deviation of the intercept to the slope of the curve. The low LOD and LOQ values are tabulated in Table 1, indicating the good sensitivity of the proposed methods.

\section{Precision}

The precision of the established procedures was also assessed in terms of intra and inter-day by analyzing three concentrations of both analytes in the calibration curve range. For intra-day solutions were analyzed tree times in day and these solutions were investigated for three succeeding days for inter day precision. The percent relative standard deviation was calculated and presented in Table 1. The result showed low percent RSD, which confirmed that the proposed methods were precise.

\section{Accuracy}

Accuracy of the projected procedures were examined by assaying different concentration of both the analytes in the calibration concentration range. The accuracy of the methods was expressed in terms of the percent recovery and percent relative error. The mean percentage recovery was $98.60 \%$ to $100.78 \%$, for RGF and $98.81 \%$ to 99.15 


\begin{tabular}{|c|c|c|c|c|}
\hline \multirow{2}{*}{$\begin{array}{l}\text { Validation } \\
\text { Parameters }\end{array}$} & \multicolumn{2}{|c|}{ Remogliflozin } & \multicolumn{2}{|c|}{ Vildagliptin } \\
\hline & SDS & $\operatorname{ccs}$ & SDS & $\operatorname{ccs}$ \\
\hline Wavelength $(\mathrm{nm})$ & 243.4 & 225.8 & 221.3 & 208.0 \\
\hline Linearity range $(\mu \mathrm{g} / \mathrm{mL})$ & $5-75$ & $2-75$ & $2-50$ & $2-50$ \\
\hline Slope & 0.022 & 0.0342 & 0.0066 & 0.0173 \\
\hline Intercept & -0.0141 & -0.012 & 0.0064 & 0.0148 \\
\hline Regression coefficient $\left(r^{2}\right)$ & 0.9997 & 0.9995 & 0.9993 & 0.9996 \\
\hline $\operatorname{LOD}(\mu \mathrm{g} / \mathrm{mL})$ & 1.38 & 0.25 & 0.31 & 0.29 \\
\hline $\mathrm{LOQ}(\mu \mathrm{g} / \mathrm{mL})$ & 4.12 & 0.76 & 0.94 & 0.89 \\
\hline Accuracy (Mean $\% \pm \% R E$ ) & $98.60 \pm 0.890$ & $100.78 \pm 1.426$ & $98.81 \pm 1.482$ & $99.15 \pm 0.849$ \\
\hline \multicolumn{5}{|c|}{ Precision (\%RSD) } \\
\hline Intra day & 1.245 & 0.943 & 0.905 & 1.098 \\
\hline Inter day & 0.852 & 1.846 & 1.067 & 0.804 \\
\hline
\end{tabular}

SDS: Second Derivative Spectrophotometric method; CCS Constant Centered Spectrophotometric method; \%RE: Percentage Relative Error

\begin{tabular}{|c|c|c|c|c|}
\hline & \multirow[t]{2}{*}{$\begin{array}{l}\text { Amount taken } \\
\qquad(\mu \mathrm{g} / \mathrm{mL})\end{array}$} & $\begin{array}{c}\text { Second Derivative } \\
\text { method }\end{array}$ & $\begin{array}{c}\text { Constant Centered } \\
\text { method }\end{array}$ & Reference Method \\
\hline & & $\%$ Recovery & $\%$ Recovery & $\%$ Recovery \\
\hline \multicolumn{5}{|c|}{ Vildagliptin } \\
\hline \multirow[t]{6}{*}{ Formulation (50 mg VGT +100 mg RGF) } & 8 & 99.45 & 98.25 & 98.00 \\
\hline & 16 & 98.54 & 99.25 & 99.50 \\
\hline & 32 & 101.36 & 100.56 & 98.89 \\
\hline & Mean & 99.78 & 99.35 & 98.79 \\
\hline & $\%$ RSD & 1.523 & 1.156 & 0.754 \\
\hline & $\mathrm{n}$ & 4 & 4 & \\
\hline \multicolumn{2}{|l|}{ Student $t$ - test $(2.776)^{\mathrm{c}}$} & 1.009 & 0.348 & \\
\hline \multicolumn{2}{|l|}{$F(19) d$} & 4.077 & 1.18 & \\
\hline \multicolumn{5}{|c|}{ Remogliflozin } \\
\hline \multirow[t]{6}{*}{ Formulation (50 mg VGT +100 mg RGF) } & 16 & 101.20 & 99.20 & 99.03 \\
\hline & 32 & 100.75 & 100.74 & 100.90 \\
\hline & 64 & 99.00 & 98.59 & 99.72 \\
\hline & Mean & 100.31 & 99.51 & 99.88 \\
\hline & $\%$ RSD & 1.162 & 1.114 & 0.957 \\
\hline & $\mathrm{n}$ & 4 & 4 & \\
\hline \multicolumn{2}{|l|}{ Student $t$ - test $(2.776)^{\mathrm{c}}$} & 0.363 & 0.436 & \\
\hline \multicolumn{2}{|l|}{$F(19) d$} & 1.411 & 1.353 & \\
\hline
\end{tabular}

${ }^{a}$ HPLC method using monolithic column ( $5 \mu \mathrm{m}, 50 \mathrm{~mm} \times 4.6 \mathrm{~mm}$ i.d.), and mobile phase acetonitrile-sodium dihydrogen phosphate (10 $\mathrm{mM}$ ) and SDS (10 $\mathrm{mM}$ ) (30/70, v/v) with $\mathrm{pH} 4.5$, flow rate of $2.5 \mathrm{~mL} / \mathrm{min} .^{31}$

${ }^{\mathrm{b}} \mathrm{HPLC}$ method using monolithic column ( $5 \mu \mathrm{m}, 50 \mathrm{~mm} \times 4.6 \mathrm{~mm}$ i.d.), and mobile phase acetonitrile and mixture of $25 \mathrm{mM}$ sodium dodecyl sulfate and $10 \mathrm{mM}$ potassium dihydrogen phosphate $\left(\mathrm{pH}_{3.5}\right)(42: 58 \mathrm{v} / \mathrm{v}) .^{19}$

c and ${ }^{d}$ are critical values of $t$ and $F$, respectively at $p=0.05$

$\%$ for VGT with low $\%$ RE, confirmed the accuracy of the projected methods (Table 1).

\section{Stability Studies}

Stock solutions of RGF and VGT were prepared and stored in a refrigerator at $4^{\circ} \mathrm{C}$. Working standards and standard solutions for method validation were prepared on daily basis. The stability of the stock and sample solutions was evaluated by analyzing the solutions stored in the refrigerator after being kept at room temperature for $5 \mathrm{~h}$ and after 7 days. The assay results of freshly prepared solutions and the stored solutions did not 
show significant differences, indicating the stability of the solutions.

\section{Application to medicinal formulations}

The proposed procedures were applied for quantitative analysis of VGT and RGF from the medicine. This amount was in agreement with the labeled quantity. The assay results confirmed that the excipients did not affect the assay performance. This indicates the specificity of the suggested approaches. Further, the assay outcomes were compared with the reported HPLC methods ${ }^{19,31}$ using the $F$-test and students $t$-test. The results indicated that there were no significant differences between the performance of the suggested and the described HPLC methods regarding precision and accuracy as the critical values of $F$ and $t$-tests were higher than the calculated values (Table 2).

\section{CONCLUSION}

In summary, a rapid and sensitive second-order derivative and constant centered spectrophotometric methods were established for the concurrent assay of VGT and RGF for the first time. The process was fully validated following the ICH recommendations. Further, the derivative spectrophotometric methods were applied to assess VGT and RGF in formulations with a high percentage recovery; of more than $98 \%$. The assay results of the formulation were in agreement with the concentration of labeled amount and no significant difference was observed in the results when compared to the reported method. Hence, the anticipated procedures could be applied for the routine quality control of formulations consisting of VGT and RGF.

\section{ACKNOWLEDGEMENT}

The authors are thankful to the Deanship of Scientific Research, King Faisal University, Al-Ahsa for financial support under the Nasher track (Grant No. 216044).

\section{CONFLICT OF INTEREST}

The authors declare that there is no conflict of interest.

\section{ABBREVIATIONS}

UV: Ultra violet; \%RE: Percentage Relative Error; \%RSD: Percent Relative Standard Deviation; International Conference on Harmonisation; DDP4: dipeptidyl peptidiase-4; SGLT-2: sodium glucose cotransporter-2; HPLC: High Performance Liquid Chromatography; UPLC: Ultra Performance Liquid
Chromatography; LCMS: Liquid Chromatography Mass spectrometry.

\section{REFERENCES}

1. New Zealand Society for the Study of Diabetes. (NZSSD), Ministry of Health. Type 2 diabetes management guidance; 2021 [cited July 2021]. Available from: https://t2dm.nzssd.org.nz/.

2. Drucker DJ, Nauck MA. The incretin system: Glucagon-like peptide-1 receptor agonists and dipeptidyl peptidase-4 inhibitors in type 2 diabetes. Lancet. 2006;368(9548):1696-705. doi: 10.1016/S0140-6736(06)69705-5, PMID 17098089.

3. Joshi SS, Singh T, Newby DE, Singh J. Sodium-glucose co-transporter 2 inhibitor therapy: mechanisms of action in heart failure. Heart. 2021;107:1032-8. doi: 10.1136/heartjnl-2020-318060, PMID 33637556.

4. Ahsan S. Effectiveness of remogliflozin and vildagliptin combination in type 2 diabetes mellitus patients uncontrolled on triple oral drug therapy. Endocr Pract. 2021;27(6);Suppl 62. doi: 10.1016/j.eprac.2021.04.600.

5. Kawanami D, Takashi Y, Takahashi H, Motonaga R, Tanabe M. Renoprotective effects of DPP-4 inhibitors. Antioxidants (Basel). 2021;10(2):246. doi: 10.3390/antiox10020246, PMID 33562528.

6. Schiapaccassa A, Maranhão PA, De Souza MDGC, Panazzolo DG, Nogueira Neto JF, Bouskela E, et al. 30-days effects of vildagliptin on vascular function, plasma viscosity, inflammation, oxidative stress, and intestinal peptides on drug-naïve women with diabetes and obesity: A randomized head-to-head metformin-controlled study. Diabetol Metab Syndr. 2019;11:70. doi: 10.1186/ s13098-019-0466-2, PMID 31462933.

7. Zelniker TA, Wiviott SD, Raz I, Im K, Goodrich EL, Bonaca MP, et al. SGLT2 inhibitors for primary and secondary prevention of cardiovascular and renal outcomes in type 2 diabetes: A systematic review and meta-analysis of cardiovascular outcome trials. Lancet. 2019;393(10166):31-9. doi: 10.1016/ S0140-6736(18)32590-X, PMID 30424892.

8. Dayoub LA, Amali F. Development of a new visible spectrophotometric analytical method for determination of vildagliptin in bulk and Pharmaceutical dosage forms. Res J Pharm Technol. 2020;13(6):2807-10. doi: 10.5958/0974360X.2020.00499.0.

9. Kumari B, Khansili A. Analytical method development and validation of UVvisible spectrophotometric method for the estimation of vildagliptin in gastric medium. Drug Res. 2020;70(9):417-23. doi: 10.1055/a-1217-0296, PMID 32746479.

10. Abdel-Ghany MF, Abdel-Aziz O, Ayad MF, Tadros MM. Validation of different spectrophotometric methods for determination of vildagliptin and metformin in binary mixture. Spectrochim Acta A Mol Biomol Spectrosc. 2014;125:175-82. doi: 10.1016/j.saa.2014.01.055, PMID 24548810.

11. Moneeb MS. Spectrophotometric and spectrofluorimetric methods for the determination of saxagliptin and vildagliptin in bulk and pharmaceutical preparations. Bull Fac Pharm Cairo Univ. 2013;51(2):139-50. doi: 10.1016/j. bfopcu.2013.03.003.

12. Shaikh NK, Jat R, Bhangale JO. Analysis of vildagliptin and nateglinide for simultaneous estimation using Spectro-chromatographic methods. Eur J Mol Clin Med. 2020;07(8):741-55.

13. Patil KR, Deshmukh TA, Patil VR. A stability indicating HPTLC method development and validation for analysis of vildagliptin as bulk drug and from its pharmaceutical dosage form. Int J Pharm Sci Res. 2020;11(5):2310-6. doi: 10.13040/IJPSR.0975-8232.11(5).2310-16.

14. Shakoor A, Ahmed M, Ikram R, Hussain S, Tahir A, Jan BM, et al. Stabilityindicating RP-HPLC method for simultaneous determination of metformin hydrochloride and vildagliptin in tablet and biological samples. Acta Chromatogr. 2020;32(1):39-43. doi: 10.1556/1326.2019.00555.

15. Hady KKA, Salam RAA, Hadad GM, Hameed EAA. Simultaneous HPLC determination of vildagliptin, ampicillin, sulbactam and metronidazole in pharmaceutical dosage forms and human urine. J Iranian Chem Soc. 2021;18:729-38 https://doi.org/10.1007/s13738-020-

16. Ferrazza Alves Giordani C, Campanharo S, Ribeiro Wingert N, Maronesi Bueno L, Wittckind Manoel J, Virginia Garcia C, et al. UPLC-ESI/Q-TOF MS/ MS Method for Determination of Vildagliptin and its Organic Impurities. J 
Chromatogr Sci. 2020;58(8):718-25. doi: 10.1093/chromsci/bmaa040. PMID 32705127.

17. Vidhi D, Patel P. Method development and validation of UV spectrophotometric estimation of remogliflozin etabonate in bulk and its tablet dosage form. Res J Pharm Technol. 2021;14(4):2042-4. doi: 10.52711/0974-360X.2021.00362.

18. Attimarad $M$, Nair $A B$, Sreeharsha $N$, Al-Dhubiab BE, Venugopala KN, Shinu P. Development and validation of green UV derivative spectrophotometric methods for simultaneous determination metformin and remogliflozin from formulation: evaluation of greenness. Int $\mathrm{J}$ Environ Res Public Health. 2021;18(2):448. doi: 10.3390/ijerph18020448, PMID 33429964.

19. Attimarad M, Elgorashe REE, Subramaniam R, Islam MM, Venugopala KN, Nagaraja S, et al. Development and validation of rapid RP-HPLC and green second-derivative UV spectroscopic methods for simultaneous quantification of metformin and remogliflozin in formulation using experimental design. Separations. 2020;7(4):5925. doi: 10.3390/separations7040059.

20. Tayade AB, Patil AS, Shirkhedkar AA. Development and Validation of Zero Order UV-Spectrophotometric Method by Area under Curve Technique and High Performance Thin Layer Chromatography for the Estimation of Remogliflozin Etabonate in Bulk and In-House Tablets. Invent. Rapid Pharm. Anal. Qual Assur. 2019;3:1-5.

21. Bhatkar T, Badkhal AV, Bhajipale NS. Stability indicating RP-HPLC method development and validation for the estimation of remogliflozin etabonate in bulk and pharmaceutical dosage form. Int J Pharmace Res. 2020;12(4).

22. Shah DA, Gondalia II, Patel VB, Mahajan A, Chhalotiya UK. Stability indicating liquid chromatographic method for the estimation of remogliflozin etabonate. J Chem Metrol. 2020;14(2):125-32. doi: 10.25135/jcm.46.20.07.1734.

23. Tammisetty MR, Challa BR, Puttagunta SB. A Novel Analytical Method for the Simultaneous Estimation of Remogliflozin and Metformin Hydrochloride by UPLC/PDA in Bulk and Formulation Application to the Estimation of Product Traces. Turk J Pharm Sci. 2021;18(3):296-305. doi: 10.4274/tjps. galenos.2020.39699, PMID 34157819.

24. Sigafoos JF, Bowers GD, Castellino S, Culp AG, Wagner DS, Reese MJ, Humphreys JE, et al. Assessment of the drug interaction risk for remogliflozin etabonate, a sodium-dependent glucose cotransporter-2 inhibitor: evidence from in vitro, human mass balance, and ketoconazole interaction studies.
Drug Metab Dispos. 2012;40(11):2090-101. doi: 10.1124/dmd.112.047258, PMID 22851617.

25. Kamal AH, El-Malla SF, Hammad SF. A Review on UV spectrophotometric methods for simultaneous multicomponent analysis. Eur J Pharm Res. 2016;3:348-60.

26. Salinas F, Nevado JJB, Mansilla AE. A new spectrophotometric method for quantitative multicomponent analysis resolution of mixtures of salicylic and salicyluric acids. Talanta. 1990;37(3):347-51. doi: 10.1016/00399140(90)80065-n, PMID 18964949.

27. Chohan MS, Elgorashe REE, Balgoname AA, Attimarad M, SreeHarsha N, Venugopala KN, et al. Eco-friendly Derivative UV Spectrophotometric Methods for Simultaneous Determination of Diclofenac Sodium and Moxifloxacin in Laboratory Mixed Ophthalmic Preparation. Indian J Pharm Educ Res. 2019;54(1):166-74. doi: 10.5530/ijper.54.1.20.

28. Bhatt NM, Chavada VD, Sanyal M, Shrivastav PS. Manipulating ratio spectra for the spectrophotometric analysis of diclofenac sodium and pantoprazole sodium in laboratory mixtures and tablet formulation. Scientific World Journal. 2014;2014:495739. doi: 10.1155/2014/495739.

29. Attimarad M, Shahzad Chohan M, Ahmed Balgoname A. Simultaneous determination of moxifloxacin and flavoxate by RP-HPLC and ecofriendly derivative spectrophotometry methods in formulations. Int $\mathrm{J}$ Environ Res Public Health. 2019;16(7):1196. doi: 10.3390/ijerph16071196, PMID 30987126.

30. Lotfy HM, Hegazy MA. Simultaneous determination of some cholesterollowering drugs in their binary mixture by novel spectrophotometric methods. Spectrochim Acta A Mol Biomol Spectrosc. 2013;113:107-14. doi: 10.1016/j. saa.2013.04.064, PMID 23711399.

31. Attimarad M, Nagaraja SH, Aldhubaib BE, Al-Najjar A. Development of a rapid reversed phase-high performance liquid chromatography method for simultaneous determination of metformin and vildagliptin in formulation and human plasma. J Young Pharm. 2014;6(4):40-6. doi: 10.5530/jyp.2014.4.7.

\section{SUMMARY}

Recently approved fixed dose combination of vildagliptin and remogliflozin etabonate are useful for the treatment of the type 2 diabetes. A simple, rapid, accurate derivative UV spectroscopic methods were established for the concurrent quantitative analysis of both the analytes. Both methods showed linearity concentrations in the range of $2-75 \mu \mathrm{g} / \mathrm{ml}$ for RGF and $2-50 \mu \mathrm{g} / \mathrm{ml}$ for VGT. The low LOD and LOQ found for RGF and VGT by both methods indicated the good sensitivity of the methods. The good percentage recovery along with low percent relative error confirmed the accuracy of the methods. The $\%$ RSD for intra and inter-day precision was less than $\pm 2 \%$. The assay results of the formulation were in agreement with the concentration of labeled amount and no significant difference was observed in the results when compared to the reported method. Hence, the anticipated procedures could be applied for the routine quality control of formulations consisting of VGT and RGF. 
PICTORIAL ABSTRACT
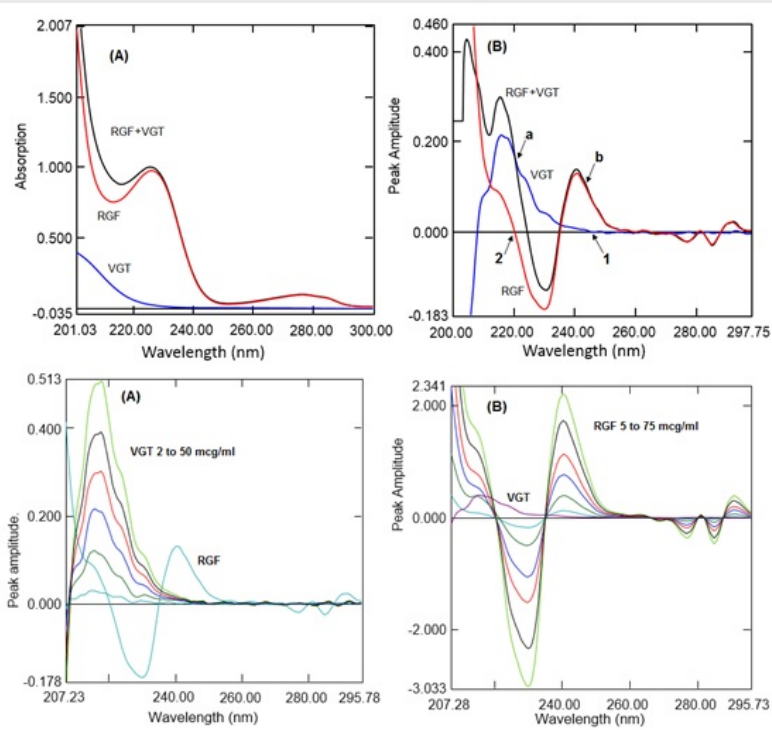

\section{About Authors}

Dr. Mahesh Attimarad is graduated from Al-Ameen College of Pharmacy and completed his doctorate in Pharmaceutical and Analytical Chemistry from Rajiv Gandhi University of Health Sciences, Bangalore, India. He teaches Pharmaceutical Organic Chemistry, Pharmaceutical Analytical chemistry and Medicinal Chemistry courses at College of Clinical Pharmacy, KFU. He is actively involved in the research and received few research grants from KFU. His major research interests include Development of new analytical methods for drug molecules for estimation in pharmaceutical formulations and body fluids (blood and urine), Microwave assisted synthesis of organic compounds, and Design and synthesis of NSAIDs and Screening for anti-inflammatory and analgesic activities.

Cite this article: Attimarad M, Venugopala KN, Shafi S, Balgoname AA, Altaysan A. Smart Spectrophotometric Method Development for Simultaneous Estimation of Antidiabetic Drugs in Formulations. Indian J of Pharmaceutical Education and Research. 2022;56(1):224-31. 